\title{
Protective effect of protocatechuic acid against inflammatory stress induced in human dermal fibroblasts
}

\author{
Ji Hye Son ${ }^{1,2}$, Soo-Yeon Kim³ ${ }^{3}$ Hyun Hee Jang ${ }^{4}$, Sung Nae Lee ${ }^{5}$ and Kyu Joong Ahn ${ }^{6 *}$
}

\begin{abstract}
Background: Protocatechuic acid (PCA) is an anthocyanin metabolite with a high antioxidant property. It is also known for having anticancer and anti-inflammatory capacities with diverse medicinal activities. As one of the active ingredients in plant sources, PCA has been studied and has revealed various mechanisms, but effects on cosmetology are not sufficient. This paper suggests the effects of PCA on cosmeceutical via antioxidant and senescence-inhibiting activities.

Methods: Prior to demonstrating PCA efficacy, we performed cell viability of PCA of 0-100 $\mu \mathrm{M}$ with or without lipopolysaccharide (LPS) using water-soluble tetrazolium salt (WST-1). Then, to evaluate the antioxidant capacity, especially excessive generated reactive oxygen species (ROS), researchers carried out ROS scavenging activity of PCA through 2',7'-dichlorodihydrofluorescein diacetate (DCFH-DA) fluorescence intensity. Cellular senescence was assessed by senescence-associated $\beta$-galactosidase (SA- $\beta$-gal)-positive value, and extracellular matrix (ECM)-associated gene expression, collagen type I, alpha 1 chain (COLIA1), and matrix metalloproteinase-1 (MMP1) were estimated through quantitative real-time polymerase chain reaction (qRT-PCR).

Results: PCA has not shown cellular toxicity under $100 \mu \mathrm{M}$, with or without LPS. The results demonstrated that PCA exerted an antioxidant effect on LPS-treated human dermal fibroblasts (HDFs), via ROS scavenging activity.

Furthermore, PCA has shown the senescence attenuating efficacy in HDFs through reducing senescent cells and regulating COLIA1 and MMP1 gene expression.
\end{abstract}

Conclusion: This work suggests the potential benefits of PCA against LPS-induced excessive ROS generation and cellular senescence, for the first time.

Keywords: Protocatechuic acid, Human dermal fibroblast, Lipopolysaccharide, Antioxidant, Senescence

\section{Background}

Polyphenols, the most focused dietary antioxidant for decades, have been reported to have not only antioxidant capacity but also biological efficacy. Phenolic acids, one of a major class of polyphenols, are naturally occurring in the plant kingdom including diverse edible plants (Tsao, 2010; Manach et al., 2004; Piazzon et al., 2012). PCA is a widely distributed phenolic compound common in human dietary plants and fruits, including plums, grapes, nuts (almonds), onion (Allium cepa L.), grain brown rice (Oryza sativa L.),

\footnotetext{
* Correspondence: kjahn@kuh.ac.kr

${ }^{6}$ Department of Dermatology, Konkuk University School of Medicine, 120

Neungdong-ro, Gwangjin-gu, Seoul 05029, Republic of Korea

Full list of author information is available at the end of the article
}

and olives (Oleaeuropaea). PCA has been researched about its biological and pharmacological properties including particular disease models. According to previous studies, PCA has anti-inflammatory, antioxidant, and free radical scavenging properties in both in vitro and in vivo reports (Khan et al., 2015; Kakkar \& Bais, 2014; Semaming et al., 2015). Aside from its antioxidant property, it is important and necessary to examine whether PCA has other potential benefits such as anti-aging effects.

Fibroblasts are the most omnipresent cells in the human dermis and are important in maintaining and structuring organs via remodeling extracellular matrix (ECM) components (Tracy et al., 2016; Eleftheriadis et al., 2011; Darby \& Hewitson, 2007; Kisseleva \& 
Brenner, 2008). The cells, fibroblasts, are also known to generate diverse cytokines to interfere with the immune system under certain conditions (Jordana et al., 1994). The endotoxin, LPS, is the major component of the outer membrane of gram-positive bacteria. It also covers about $90 \%$ of the cell surface and then serves as a physical barrier (Rosenfeld \& Shai, 2006; Hancock \& Diamond, 2000; Nikaido, 1989; Papo \& Shai, 2005). In biological properties, it has been reported that LPS recruits immune cells to human dermal fibroblasts (HDFs) via inducing the progression of inflammatory processes through secretion of soluble mediators (Gasparrini et al., 2017; Tardif et al., 2004; Wheater et al., 2012). Moreover, the ECM is also capable of influencing cell migration, senescence, and gene expression of the fibroblasts (Tracy et al., 2016; Majno et al., 1971). Focusing on the above results, this study aims to investigate LPS-induced ROS scavenging capacity and suppressing activity of PCA in cellular senescence phenomena. This study is the first to verify the protective effect of PCA on LPS-induced damages in HDF cells.

\section{Methods}

\section{Cell culture}

The HDFs derived from human skin cells were obtained from the Lonza Group (Basel, Switzerland) and were maintained in DMEM supplemented with $10 \%$ heatinactivated FBS, 100 units $/ \mathrm{mL}$ penicillin, and $100 \mu \mathrm{g} / \mathrm{ml}$ streptomycin in a humidified atmosphere of $5 \% \mathrm{CO}_{2}$ at $37{ }^{\circ} \mathrm{C}$. For subculture, the medium was eliminated and cells were rinsed with PBS twice. Then, cells detached using trypsin-EDTA were cultured with fresh complete growth medium in a ratio of $1: 5$ every $72 \mathrm{~h}$. Protocatechuic acid was diluted with the culture medium before treatment, and final concentrations were adjusted using DMSO.

\section{Cell cytotoxicity}

The cytotoxicity was determined using an WST-1 assay kit following the manufacturer's protocol. Briefly, the cells were seeded in the culture plate, incubated for $24 \mathrm{~h}$, and then treated with diverse concentrations of protocatechuic acid $(25,50,75$, and $100 \mu \mathrm{M})$ for $24 \mathrm{~h}$ with or without $1 \mu \mathrm{g} / \mathrm{mL}$ of LPS. Then, $10 \mu \mathrm{L}$ of EZ-Cytox cell viability assay kit reagent (ItsBio, Korea) was added to the cultured cells and the cells were incubated for $1 \mathrm{~h}$. The absorbance was measured at $490 \mathrm{~nm}$ using a microplate reader (Bio-Rad, Hercules, CA, USA). The mean and standard deviation of cell viability was calculated after repeating the procedure three times.

\section{DCFH-DA scavenging assay}

The intracellular ROS generation was measured using the fluorescence dye DCFH-DA, which produces a detectable fluorescence when the non-fluorescent DCFH reacts with ROS in cells. The treated cells were incubated with $25 \mu \mathrm{M}$ DCFH-DA at $37{ }^{\circ} \mathrm{C}$ for $1 \mathrm{~h}$ and then the fluorescence intensity was measured using a $\mathrm{BD}$ fluorescence-activated cell sorting calibur (FACSCalibur, flow cytometer, BD Biosciences, San Jose, CA, USA), at excitation and emission wavelengths of 485 and $535 \mathrm{~nm}$, respectively.

\section{SA- $\beta$-gal activity}

SA- $\beta$-gal staining was carried out according to the manufacturer's instructions, and senescence cell staining was detected $24 \mathrm{~h}$ after treatment. Briefly, the cells were rinsed twice with PBS, fixed with $0.5 \mathrm{ml}$ fixative solution (4\% formaldehyde and $0.5 \%$ glutaraldehyde in PBS, $\mathrm{pH}$ 7.2) for $20 \mathrm{~min}$, rinsed again with PBS, and then were incubated with the staining solution for $24 \mathrm{~h}$ at $37{ }^{\circ} \mathrm{C}$. Then, the staining solution was removed, and $70 \%$ glycerol was added to each well before the stained cells were examined for senescence using a microscope (Olympus Microscope System IX51, Olympus, Japan).

\section{RNA isolation and qRT-PCR}

The total RNA of each sample was isolated using the TRIzol reagent following the manufacturer's protocol. After the purified RNA had been validated using a spectrophotometer (MaestroNano, Maestrogen, NV, USA), $1 \mu \mathrm{g}$ of the total RNA was used for cDNA synthesis using a miScript II RT kit. The mRNA expression was quantitatively assessed using Evagreen dye with the Line-Gene K software (BioER, Hangzhou, China), according to the manufacturer's protocol. The primers for the qRT-PCR are $\beta$-actin (Forward: GGATTCCT ATGTGGGCGACGA, Reverse: CGCTCGGTGAGG ATCTTCATG), COL1A1 (Forward: AGGGCCAAGACG AAGACATC, Reverse: AGATCACGTCATCGCACAA CA) and $M M P 1$ (Forward: TCTGACGTTGATCCCAGA GAGCAG, Reverse: CAGGGTGACACCAGTGACTGC $A C)$. And the experiment was performed in triplicate.

\section{Statistics}

All the results are presented as the mean percentage \pm standard deviation (SD) of three independent experiments. $p$ values $<0.05,0.01$, and 0.001 were considered statistically significant and were determined using Student's $t$ test.

\section{Results}

\section{Cytotoxicity of LPS and PCA in HDF cells}

We observed cytotoxicity of LPS and PCA on HDF cells using WST-1 assay. Researchers treated PCA $(0-100 \mu \mathrm{M})$ on HDF cells for $24 \mathrm{~h}$ with or without LPS $(1 \mu \mathrm{g} / \mathrm{mL})$. As shown in Fig. 1, indicated concentrations of PCA and LPS have no significant cytotoxicity. Based on these results, we 


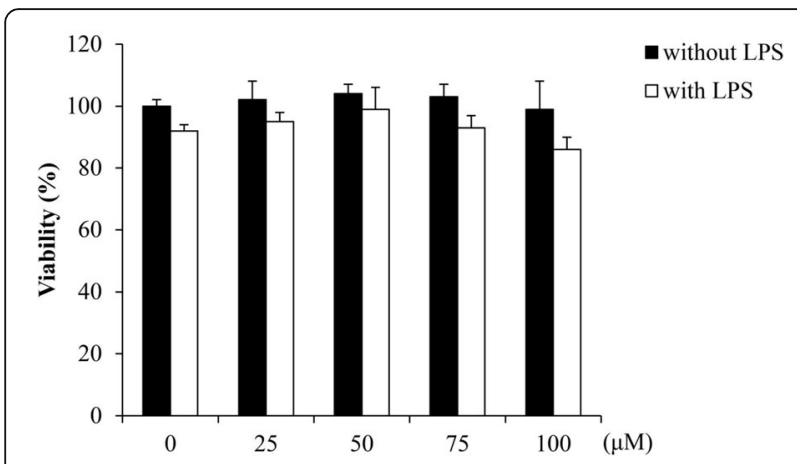

Fig. 1 Cytotoxicity of PCA with or without LPS in HDF cells. Cell viability in HDF cells were measured by WST-1 assay with different concentrations of PCA $(0-100 \mu \mathrm{M})$ and LPS $(1 \mu \mathrm{g} / \mathrm{mL})$ for $24 \mathrm{~h}$. Black bar represents the cell viability of indicated concentrations of PCA without LPS treatment. White bar represents the cell viability of PCA co-treated with LPS. Data are expressed as mean \pm standard deviation

examined further experiments, antioxidant effect by measuring ROS scavenging capacity and antisenescence efficacy via senescent cell counting, and ECM-modulating gene expression analysis, at various concentrations of PCA.

\section{Intracellular excessive ROS scavenging effect of PCA in HDF cells}

Estimating intracellular ROS concentrations could explain the quantitative oxidative stress induced by a stimulus. LPS, an endotoxin released from gram-negative bacteria, has been reported to induce intracellular ROS production and acute injuries (Kim et al., 2012). Thus, this study demonstrated whether PCA reduces intracellular ROS induced by LPS in HDF cells via DCFH-DA assay. As a result, $1 \mu \mathrm{g} / \mathrm{mL}$ LPS-treated HDFs for $24 \mathrm{~h}$ showed increased DCF fluorescent intensity while cells treated with diverse PCA with LPS indicated significantly reduced DCF intensity (Fig. 2). A significant reduction in the DCF fluorescent intensity compared to the LPS treatment was 50 and $100 \mu \mathrm{M}$ of PCA-treated cells $(* p<0.05)$.

\section{Attenuation effects of PCA on cellular senescence and ECM-modulating gene expression in HDF cells}

Next, researchers carried out the efficacy of PCA on LPSinduced cellular senescence. As shown in Fig. 3a, the LPStreated cells prominently expressed cellular senescence 3.8 -fold $(30.7 \pm 4.1)$ more than the non-treated control cells $(8.0 \pm 1.9)$. The increased senescent proportion by LPS was significantly reduced in a dose-dependent manner of PCA. The cellular senescence of HDFs was diminished to $16.3 \pm 1.1$ and $11.9 \pm 2.0$ at 50 and $100 \mu \mathrm{M}$ of PCA, respectively. In accordance with cellular senescence estimation, mRNA expression of COL1A1 and MMP1 were measured using qRT-PCR. In this study, LPS-treated cells indicated downregulated COL1A1 expression whereas PCA co-treated cells presented significantly

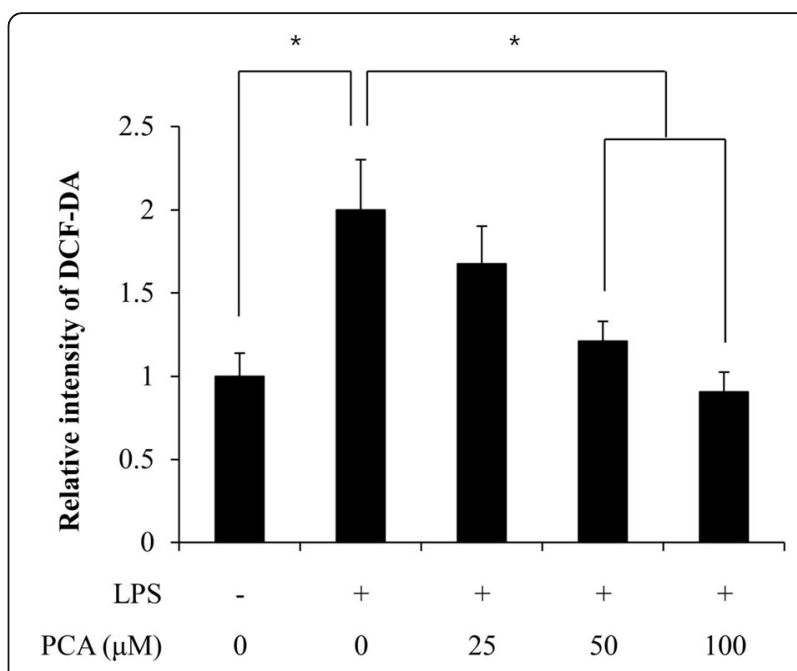

Fig. 2 Excessive ROS scavenging effect of PCA in HDF cells. Effect of PCA on excessive-generated intracellular ROS scavenging capacity was determined by DCF-DA fluorescent intensity. HDF cells had been treated with LPS $(1 \mu \mathrm{g} / \mathrm{mL})$ and PCA for $24 \mathrm{~h}$ and then were reacted with DCFH-DA $(25 \mu \mathrm{M})$. Data are expressed as mean \pm standard deviation of triplicate experiments $\left({ }^{*} p<0.05\right)$

induced expression (Fig. 3b). Interestingly, cells treated with LPS showed increasing MMP1 mRNA expression while the PCA co-treated cells reduced expression in a dose-dependent manner of PCA (Fig. 3c).

\section{Discussion}

PCA, one of phenolic acid, is widely distributed in edible plants and fruits and has been reported to have biological activities such as antioxidant, antibacterial, anticancer, antiviral, and anti-inflammatory. In this study, the data showed novel potential of PCA focused on skin cellular mechanisms. In indicated concentrations $(0-100 \mu \mathrm{M})$, PCA had no cytotoxicity in HDF cells with or without LPS $(1 \mu \mathrm{g} / \mathrm{mL})$. According to previous studies, LPS has been reported to contribute to inflammatory response including ROS generation. For this reason, it is important to investigate how dermal fibroblasts regulate LPS-induced stress and research cellular senescence. PCA treatment had efficacious consequences on preventing LPS-induced cellular senescence and ECM-related gene expression, especially COL1A1 and MMP1 mRNA. Collagen, the most abundant protein in the animal kingdom, is identified with 28 types; even collagen I comprises approximately $90 \%$ of the total collagen in the skin (Tracy et al., 2016; Eyre, 1980). And MMPs, which remodel ECM through degradation, are upregulated to diminution of collagen matrices via downregulation of type I collagen in the normal healing process (Tracy et al., 2016). It is also reported in inflammatory process that MMPs induce degradation of ECM for making easier 

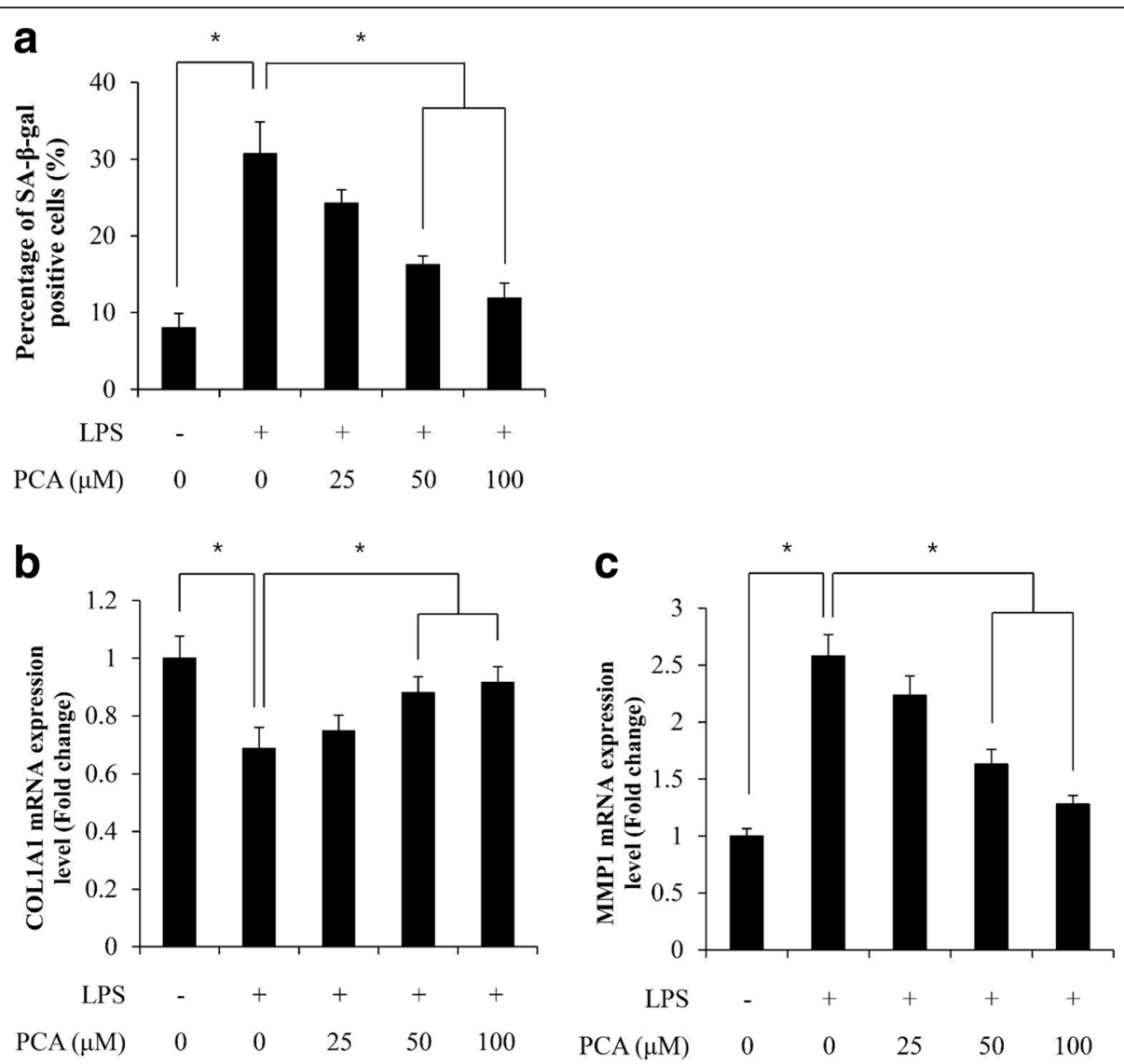

Fig. 3 Senescence-attenuating effect of PCA in HDF cells. a Effect of PCA on cellular senescence was determined by SA- $\beta$-gal assay. HDF cells had been co-treated with LPS $(1 \mu \mathrm{g} / \mathrm{mL})$ and the indicated concentration of PCA for $24 \mathrm{~h}$, then SA- $\beta$-gal assay was conducted to determine cellular senescence. $\mathbf{b}$ COL1A1 and $\mathbf{c}$ MMP1 mRNA expression were determined by qRT-PCR, and $\beta$-actin expression was used for normalization. HDF cells were treated with LPS $(1 \mu \mathrm{g} / \mathrm{mL})$ and the indicated concentration of PCA for $24 \mathrm{~h}$. Data are expressed as mean \pm standard deviation $\left.{ }^{*} p<0.05\right)$

invasion and damages (Eleftheriadis et al., 2011). In detail, 50 and $100 \mu \mathrm{M}$ of PCA showed a significant result that reduced senescent cell portion and ECM collapse promoting enzymes and $M M P 1$ gene expression. Also, COL1A1, gene of type I collagen which is the most abundant structural protein of ECM expression, was increased in 50 and $100 \mu \mathrm{M}$ of PCA-treated fibroblast cells. In this study, $25 \mu \mathrm{M}$ of PCA is not sufficient for suppressing LPS-induced stress, while 50 and $100 \mu \mathrm{M}$ of PCA reveal significant efficacy on the aims of this study.

\section{Conclusion}

Intracellular ROS are elaborately modulated by diverse antioxidant mechanisms under normal circumstances. But the excessive generation of ROS via intrinsic or extrinsic stimuli could lead to imbalance of cellular homeostasis which eventually causes damages or functional disorder in organisms. Skin, the outermost organ which protects the body from dehydration and physical or chemical irritations, has been regarded to be a representative and tangible object for figuring out aging phenomena. Focused on this point, researchers investigated how PCA protects HDF cells from LPS-induced stress through estimation of ROS scavenging capacity, senescent cell, and senescence-associated gene expression analysis. As shown in this study, PCA adduces efficacy on excessive-generated ROS scavenging and attenuating dermal fibroblast senescence. This is not enough to fully suggest cellular mechanisms of PCA on the skin but, after further studies about detailed cellular or clinical efficacy trials, could reveal the potential of PCA against varied occasions including LPS-induced symptoms.

\section{Abbreviations}

COL 1A1: Collagen type I alpha 1 chain; DCFH-DA: 2',7'-

Dichlorodihydrofluorescein diacetate; ECM: Extracellular matrix; HDFs: Human dermal fibroblasts; LPS: Lipopolysaccharide; MMP1: Matrix metalloproteinase1: PCA: Protocatechuic acid; GRT-PCR: Quantitative real-time polymerase chain reaction; ROS: Reactive oxygen species; SA- $\beta$-gal: Senescenceassociated $\beta$-galactosidase; WST-1: Water-soluble tetrazolium salt

\section{Acknowledgements}

This work was supported by a grant from the Korean Health Technology R\&D Project (Grant No. HN13C0075), Ministry of Health \& Welfare, Republic of Korea. 


\section{Funding}

Not applicable.

\section{Availability of data and materials}

Not applicable.

\section{Authors' contributions}

JHS and KJA conducted the study and drafted the manuscript. All authors analyzed data and reviewed literatures. JHS and KJA wrote the manuscript. All authors read and approved the final manuscript.

\section{Ethics approval and consent to participate}

Not applicable.

\section{Consent for publication}

Not applicable.

\section{Competing interests}

The authors declare that they have no competing interests.

\section{Publisher's Note}

Springer Nature remains neutral with regard to jurisdictional claims in published maps and institutional affiliations.

\section{Author details}

'Department of Bioengineering, Graduate School of Konkuk University, Seoul 05029, Republic of Korea. ${ }^{2}$ Lemon Beauty Academy, Busan 47837, Republic of Korea. ${ }^{3}$ Department of Beauty Art, Doowon Technical University, Paju-si, Gyeonggi-do 10838, Republic of Korea. ${ }^{4}$ School of Cosmetology, Kyungbok University, Namyangju-si, Gyeonggi-do, Republic of Korea. ${ }^{5}$ Department of Cosmetology, Kyungin Women's University, Incheon 21041, Republic of Korea. ${ }^{6}$ Department of Dermatology, Konkuk University School of Medicine, 120 Neungdong-ro, Gwangjin-gu, Seoul 05029, Republic of Korea.

Received: 20 July 2017 Accepted: 19 December 2017

Published online: 10 February 2018

\section{References}

Darby IA, Hewitson TD. Fibroblast differentiation in wound healing and fibrosis. Int Rev Cytol. 2007;257:143-79.

Eleftheriadis T, Liakopoulos V, Lawson B, Antoniadi G, Stefanidis I, Galaktidou G. Lipopolysaccharide and hypoxia significantly alters interleukin-8 and macrophage chemoattractant protein-1 production by human fibroblasts but not fibrosis related factors. Hippokratia. 2011;15:238-43.

Eyre DR. Collagen: molecular diversity in the body's protein scaffold. Science. 1980;207:1315-22.

Gasparrini M, Forbes-Hernandez TY, Giampieri F, Afrin S, Mezzetti B, Quiles JL, et al. Protective effect of strawberry extract against inflammatory stress induced in human dermal fibroblasts. Molecules. 2017; https://doi.org/10. 3390/molecules22010164.

Hancock RE, Diamond G. The role of cationic antimicrobial peptides in innate host defences. Trends Microbiol. 2000;8:402-10.

Jordana M, Särnstrand B, Sime PJ, Ramis I. Immune-inflammatory functions of fibroblasts. Eur Respir J. 1994;7:2212-22.

Kakkar S, Bais S. A review on protocatechuic acid and its pharmacological potential. ISRN Pharmacol. 2014; https://doi.org/10.1155/2014/952943.

Khan AK, Rashid R, Fatima N, Mahmood S, Mir S, Khan S, Jabeen N, Murtaza G. Pharmacological activities of protocatechuic acid. Acta Pol Pharm. 2015;72: 643-50.

Kim CO, Huh AJ, Han SH, Kim JM. Analysis of cellular senescence induced by lipopolysaccharide in pulmonary alveolar epithelial cells. Arch Gerontol Geriatr. 2012;54:e35-41.

Kisseleva T, Brenner DA. Fibrogenesis of parenchymal organs. Proc Am Thorac Soc. 2008:5:338-42.

Majno G, Gabbiani G, Hirschel BJ, Ryan GB, Statkov PR. Contraction of granulation tissue in vitro: similarity to smooth muscle. Science. 1971;173:548-50.

Manach C, Scalbert A, Morand C, Rémésy C, Jiménez L. Polyphenols: food sources and bioavailability. Am J Clin Nutr. 2004;79:727-47.

Nikaido $\mathrm{H}$. Outer membrane barrier as a mechanism of antimicrobial resistance. Antimicrob Agents Chemother. 1989;33:1831-6.
Papo N, Shai Y. A molecular mechanism for lipopolysaccharide protection of gram-negative bacteria from antimicrobial peptides. J Biol Chem. 2005;280: 10378-87.

Piazzon A, Vrhovsek U, Masuero D, Mattivi F, Mandoj F, Nardini M. Antioxidant activity of phenolic acids and their metabolites: synthesis and antioxidant properties of the sulfate derivatives of ferulic and caffeic acids and of the acyl glucuronide of ferulic acid. J Agric Food Chem. 2012;60:12312-23.

Rosenfeld Y, Shai Y. Lipopolysaccharide (Endotoxin)-host defense antibacterial peptides interactions: role in bacterial resistance and prevention of sepsis. Biochim Biophys Acta. 2006;1758:1513-22.

Semaming Y, Pannengpetch P, Chattipakorn SC, Chattipakorn N. Pharmacological properties of protocatechuic acid and its potential roles as complementary medicine. Evid Based Complement Alternat Med. 2015; https://doi.org/10. 1155/2015/593902.

Tardif F, Ross G, Rouabhia M. Gingival and dermal fibroblasts produce interleukin1 beta converting enzyme and interleukin-1 beta but not interleukin-18 even after stimulation with lipopolysaccharide. J Cell Physiol. 2004;198:125-32.

Tracy LE, Minasian RA, Caterson EJ. Extracellular matrix and dermal fibroblast function in the healing wound. Adv Wound Care (New Rochelle). 2016;5: 119-36. https://www.ncbi.nlm.nih.gov/pubmed/26989578

Tsao R. Chemistry and biochemistry of dietary polyphenols. Nutrients. 2010;2: $1231-46$.

Wheater MA, Falvo J, Ruiz F, Byars M. Chlorhexidine, ethanol, lipopolysaccharide and nicotine do not enhance the cytotoxicity of a calcium hydroxide pulp capping material. Int Endod J. 2012:45:989-95.

\section{Submit your next manuscript to BioMed Central and we will help you at every step:}

- We accept pre-submission inquiries

- Our selector tool helps you to find the most relevant journal

- We provide round the clock customer support

- Convenient online submission

- Thorough peer review

- Inclusion in PubMed and all major indexing services

- Maximum visibility for your research

Submit your manuscript at www.biomedcentral.com/submit
Biomed Central 